\title{
SAFETY CONCEPT FOR HAZARDS CAUSED BY ICE AVALANCHES FROM THE WHYMPER HANGING GLACIER IN THE MONT BLANC MASSIF
}

\author{
Stefan Margreth ${ }^{1 \star}$, Martin Funk ${ }^{2}$, Marco Vagliasindi ${ }^{3}$ and Massimo Broccolato ${ }^{4}$ \\ ${ }^{1}$ WSL Institute for Snow and Avalanche Research SLF, Davos Dorf, Switzerland \\ ${ }^{2}$ Laboratory of Hydraulics, Hydrology and Glaciology VAW, ETH Zurich, Switzerland \\ ${ }^{3}$ Fondation Montagne Sûre, Courmayeur, Italy \\ ${ }^{4}$ Regione Autonoma Valle d'Aosta, Quart, Italy
}

\begin{abstract}
The Whymper glacier is a hanging glacier located on the south face of the Grandes Jorasses (Mont Blanc Massif, Italy). Combined snow and ice avalanches triggered by ice masses breaking off from the hanging glacier endanger the village of Planpincieux and its surroundings in the Val Ferret. In 1997 the SLF and the VAW developed a first safety concept for different scenarios based on the monitoring of the glacier and an assessment of the local avalanche hazard. At the end of June 1998 almost the entire Whymper glacier (around 150'000 $\mathrm{m}^{3}$ ) sheared off and the ice avalanche stopped only $500 \mathrm{~m}$ above the valley road. Until 2009 the Whymper glacier grew again and now has a similar surface topography as in 1998. The SLF and VAW improved the 1997 safety concept by considering several scenarios of falling ice volumes. The different ice avalanche scenarios were simulated using the 2-dimensional calculation model RAMMS. The necessary safety measures are defined in relation to the local avalanche danger level and the potential volume of an icefall. The improved safety concept was in operation in winter 2009/10. However, no dangerous icefall has occurred yet.
\end{abstract}

KEYWORDS: ice avalanche, safety concept, hazard map

\section{INTRODUCTION}

The Whymper hanging glacier is an unbalanced cold ramp glacier located on the south face of the Grandes Jorasses (Mont Blanc Massif, Italy; Figs.1 and 2) at an elevation of $4000 \mathrm{~m}$ a.s.l. (Pralong and Funk 2006). Snow avalanches and combined snow-ice avalanches triggered by ice masses breaking off from the hanging glacier can endanger the village of Planpincieux and its surroundings in the Val Ferret (Fig. 3). In winter and summer the valley is heavily frequented by tourists. For the local authorities responsible for safety in the Val Ferret the key problem is to arrange the necessary safety measures by taking into account both the local avalanche danger and the risk of an impending icefall. In 1997 the SLF and the VAW worked out a first safety concept for different scenarios based on different volumes of icefalls and the local avalanche hazard (Margreth and Funk 1998). If an ice avalanche with a volume

* Corresponding author address:

Stefan Margreth,

WSL Institute for Snow and Avalanche Research

(SLF), Flüelastrasse 11, CH-7260 Davos Dorf, Switzerland, tel: +41 81417 0254;

fax: +41 81417 0111; e-mail: margreth(at)slf.ch of $30,000 \mathrm{~m}^{3}$ is released in winter in combination with a stable snowpack we recommended to close the road into the Val Ferret. However if the snowpack stability is considered to be poor we proposed to evacuate the village of Planpincieux.

In the night between 31 May and 1 June 1998 almost the entire Whymper glacier (around $150,000 \mathrm{~m}^{3}$ ) sheared off. The avalanche stopped $500 \mathrm{~m}$ above the road into the Val Ferret (Fig. 3). The horizontal and vertical distances were $3000 \mathrm{~m}$ and $2200 \mathrm{~m}$ respectively. After this event the ice avalanche activity was strongly reduced. However, the hanging glacier progressively grew and in 2009 the volume of the Whymper glacier and its geometry were very similar compared to 1997 (Fig. 2). In autumn 2008 a crevasse opened in the lower part of the hanging glacier and the occurrence of a new instability was suspected by the local autorities. In the following SLF and VAW were mandated to revise the 1997 safety concept (Margreth 2009).

2. GLACIOLOGICAL, TOPOGRAPHICAL AND AVALANCHE SITUATION

The current ice volume of the Whymper glacier is estimated to be $1500^{\prime} 000-200^{\prime} 000 \mathrm{~m}^{3}$. The front of the glacier is about $90 \mathrm{~m}$ wide and its surface is about $25^{\prime} 000 \mathrm{~m}^{2}$. The normal ablation zone of the hanging glacier is the glacier front 

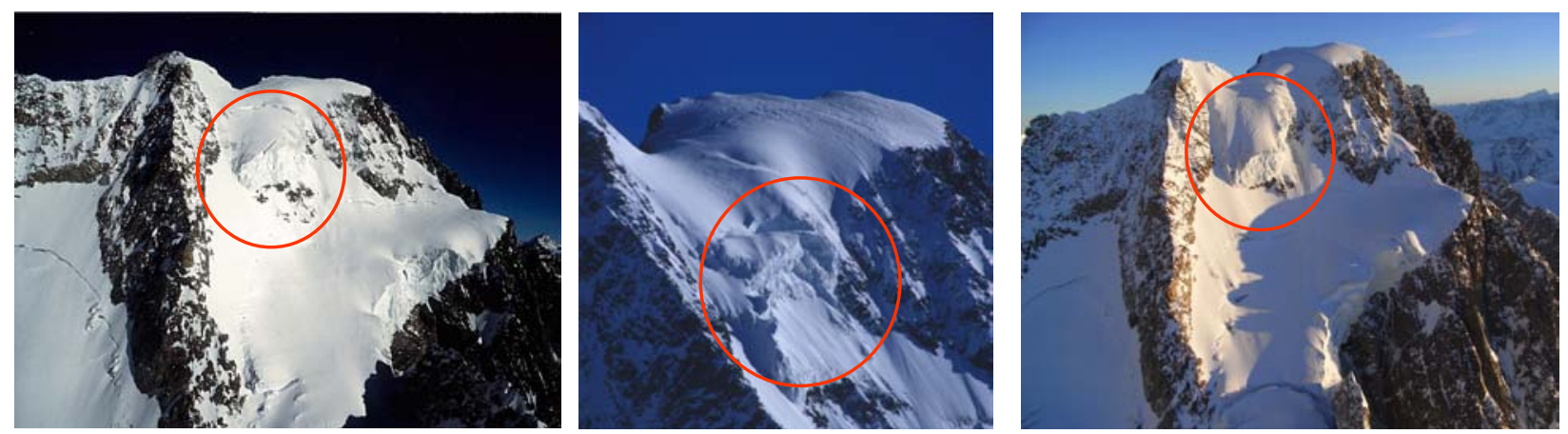

Fig. 1: Whymper glacier, Grandes Jorasses - January 1997 (left), after 1 June 1998 icefall (middle, Photo R. Cosson), January 2009 (right)

where ice lamellas with typical volumes of less than $300^{\prime} 000 \mathrm{~m}^{3}$ break off periodically. The return period is estimated to be 1 - 2 years. According to observations these smaller icefalls come to a stop above the valley floor if they occur in summer or in winter in the presence of a stable snowpack. A secondary release of snow avalanches has not been documented. As the current geometry of the Whymper glacier is comparable to that in 1997 the whole ice mass could detach again. We estimate the return period of such an icefall to be at least 15 - 30 years. Since our investigations in 1997 the area and the length of the glaciers have become somewhat smaller. However, the main features relevant for the avalanche flow such as the extent of the strongly crevassed zones or the ice surface geometry at separation points of the avalanche flow are comparable. The four main avalanche tracks that we distinguished in 1997 are still valid (Fig. 3). The extent of possible starting zones for snow avalanches is very large, with an area of about 180 ha. Because of the steep avalanche tracks with mean inclinations of $28^{\circ}$ $33^{\circ}$, the elevation difference of up to $2400 \mathrm{~m}$ and the rocky outcrops the formation of powder avalanches is likely. For the hazard assessment and the elaboration of the safety concept we investigated three different classes of ice volumes breaking off from Whymper glacier:

- Small ice volume $<101000 \mathrm{~m}^{3}$ (unforeseeable event)

- Medium ice volume of ca. 30'000 $\mathrm{m}^{3}$ (ice lamella on the glacier front)

- Maximum ice volume of ca. 150'000 m³ (slab fracture of the whole Whymper glacier)

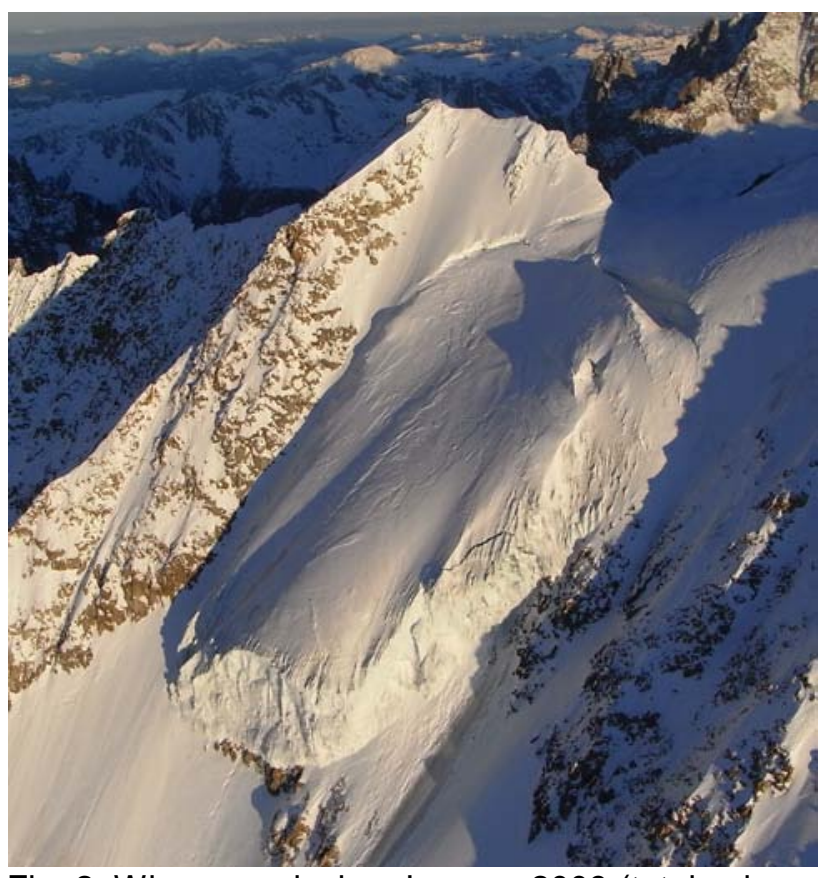

Fig. 2: Whymper glacier, January 2009 (total volume ca. $150 ` 000-200 ` 000 \mathrm{~m}^{3}$ ).

\section{AVALANCHE DYNAMICS CALCULATIONS 3.1 Fundamentals}

The goal of the avalanche dynamics calculations is to quantify the runout distances of different avalanche scenarios in relation to the three volume classes of icefalls and varying snow conditions. The main difficulty is to assess the consequences of the impact of an icefall on the snowpack. The largest known avalanche events in tracks which are within the reach of icefalls are typically observed in winter and consist of combined snow/ice-avalanches (such as the events at Weisshorn east face glacier, Randa, Switzerland or Gutzgletscher, Bernese Alps, Switzerland; Raymond 2003). Well documented cases are very rare. If a small or medium ice volume impacts a 


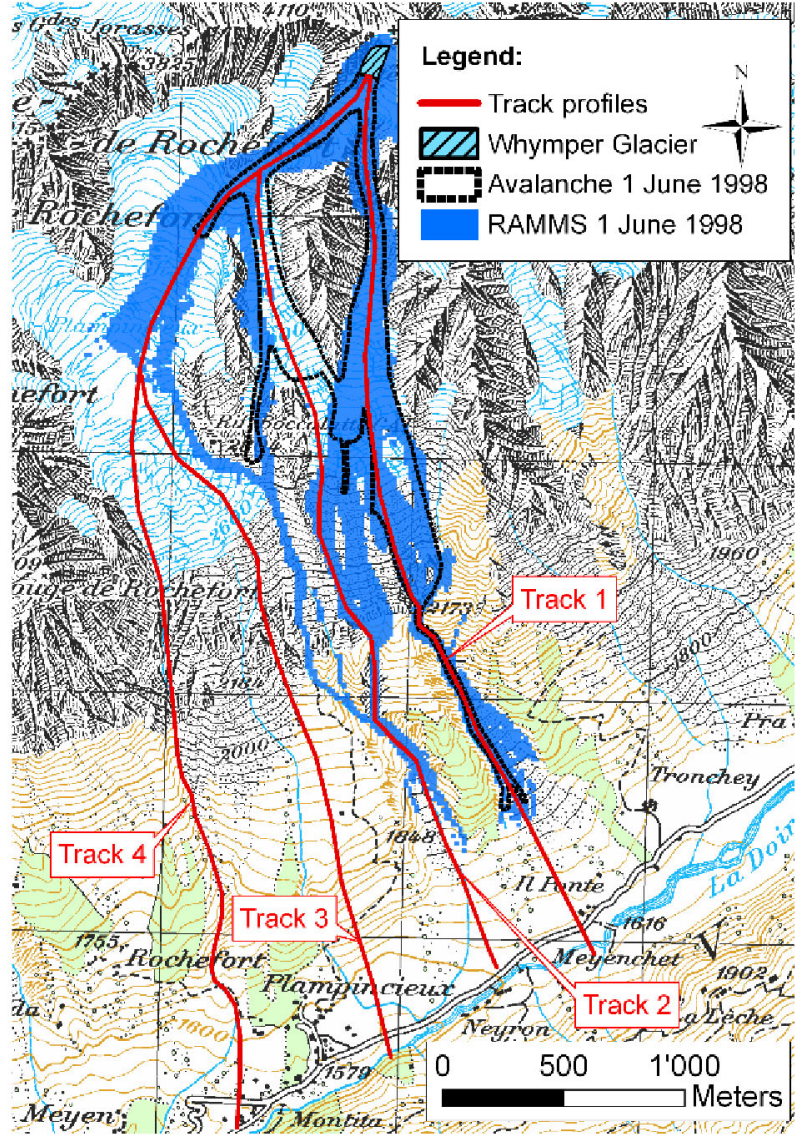

Fig. 3: Extent 1 June 1998 ice avalanche with possible tracks and RAMMS simulation.

stable snowpack, snow can be entrained. However, according to our observations the release of a secondary snow avalanche is unlikely. The approximately $25^{\prime} 000 \mathrm{~m}^{3}$ icefall of the Whymper glacier in January 1997 did not release a snow avalanche. If the impact is caused by a large ice volume $\left(>100 \cdot 000 \mathrm{~m}^{3}\right)$ or if the snowpack is unstable, the release of a secondary snow avalanche is more likely.

Interesting observations where rock avalanches impacted snow covered slopes or snow covered glaciers have been reported. On January 181997 the impact of a falling rock volume of 2 $10^{6} \mathrm{~m}^{3}$ on the Brenva glacier mobilized more than $4.510^{6} \mathrm{~m}^{3}$ of ice and snow along the track (Deline 2009). The horizontal and vertical distances were $5500 \mathrm{~m}$ and $2150 \mathrm{~m}$ respectively. On 24 December 2008 the Crammont rock avalanche, $10 \mathrm{~km}$ east of Mont Blanc, reached a horizontal and vertical distance of $3400 \mathrm{~m}$ and $1560 \mathrm{~m}$ respectively with an initial rock volume of $0.410^{6} \mathrm{~m}^{3}$ (Deline

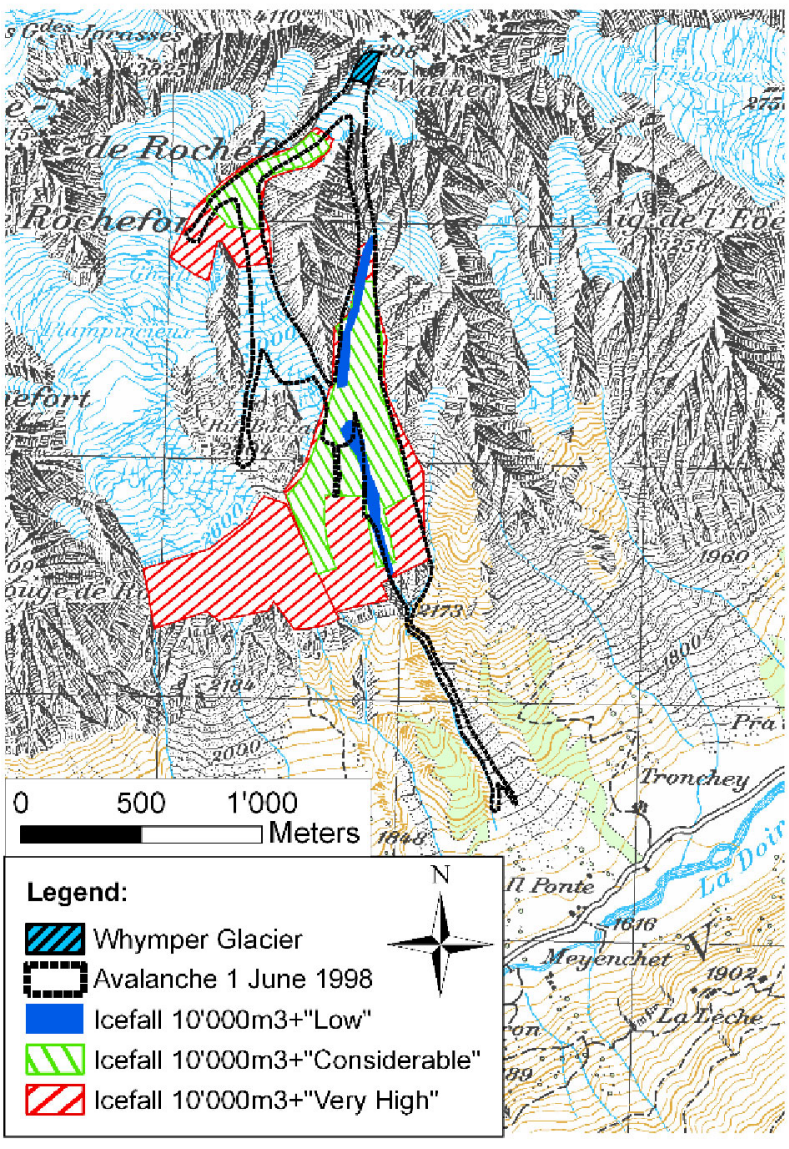

Fig. 4: Whymper glacier, extent of 1 June 1998 ice avalanche and potential snow entrainment areas for an icefall volume of $10^{\prime} 000 \mathrm{~m}^{3}$ and three different danger levels.

2010). Such long runout distances of mixed avalanche events occur because entrained ice and snow reduce the friction and fluidize the moving mass. In the Whymper glacier case we assume that an icefall with a maximum volume of 150 '000 $\mathrm{m}^{3}$ will release or entrain most of the snow pack. However, we do not expect the glaciers along the avalanche track to be eroded. As the potential snow avalanche volume below the Grandes Jorasses is much larger than the largest expected falling ice volume, the runout distances of such combined snow/ice-avalanches will be similar to what was observed in the case of snow avalanche events. We expect that the friction of a pure snow avalanche is smaller than that of a mixed snow/ice-avalanche. A mixed snow/ice avalanche is expected to behave more similarly to wet snow avalanches because of heavy impacts of ice clods and the high flow density. 
Tab. 1: Entrainment parameters in relation to the snow pack stability $(\mathrm{K}=0$ : no snow entrainment; $\mathrm{K}=1$ : the whole snowpack will be entrained) and applied friction values. In RAMMS the friction value category depends on the avalanche volume (small, medium and large) and the return periods (30, 100 and 300 years).

\begin{tabular}{|c|c|c|c|c|c|c|}
\hline \multirow[t]{2}{*}{$\begin{array}{l}\text { Snowpack sta- } \\
\text { bility }\end{array}$} & \multicolumn{2}{|c|}{$\begin{array}{l}\text { Entrainment, snow } \\
\text { density } 200 \mathrm{~kg} / \mathrm{m}^{3}\end{array}$} & \multicolumn{3}{|c|}{$\mu / \xi$ Friction value category } & Danger level \\
\hline & $\begin{array}{c}\text { Snow } \\
\text { depth } \\
(\mathrm{m})\end{array}$ & $\begin{array}{c}\text { Para- } \\
\text { meter K }\end{array}$ & $\begin{array}{l}\text { Ice volume } \\
10^{\prime} 000 \mathrm{~m}^{3}\end{array}$ & $\begin{array}{l}\text { Ice volume } \\
300^{\prime} 000 \mathrm{~m}^{3}\end{array}$ & $\begin{array}{l}\text { Ice volume } \\
1500^{\prime} 000 \mathrm{~m}^{3}\end{array}$ & \\
\hline High & $0.4-0.5$ & 0.2 & Small,10 y. & Medium,10 y. & Large 30 y. & 1 "Low" \\
\hline Moderate & 0.4-0.6 & $0.4-1$ & Medium,10 y. & Large $10 \mathrm{y}$. & Large $30 \mathrm{y}$ & 2 "Moderate" \\
\hline Moderate-Weak & 0.6 & 1 & Medium,10 y. & Large 10 y. & Large 30 y. & 3 "Considerable" \\
\hline Weak & 1.5 & 1 & Large, 30 y. & Large $100 \mathrm{y}$. & Large $300 \mathrm{y}$. & 4/5 "High"/"Very high" \\
\hline
\end{tabular}

\subsection{Models applied}

The ice avalanches were simulated with the 2-dimensional avalanche calculation model RAMMS (SLF 2010). RAMMS was specially designed as a practical tool for the calculation of snow avalanches, debris flows and rock fall. RAMMS numerically solves a system of partial differential equations, governing the depth averaged balance laws for mass, momentum and random kinetic energy using first and second order finite volume techniques. The computational grid was generated from a Digital Elevation Model with a $10 \mathrm{~m}$ resolution. The hazard assessment in 1997 was based on the results of 1-dimensional avalanche calculations with the model AVAL-1D (SLF 2005) where the primary flow directions, the flow width and the mass distributions had to be determined in advance. This is problematic in the case of a highly complex topography such as the avalanche flow path below the Grandes Jorasses. RAMMS is more appropriate for such rough terrain conditions resulting in a more reliable distribution of the avalanche mass along the different tracks. In the past years we have successfully used RAMMS for the calculation of snow avalanches. However, the model is not yet well calibrated for the calculation of ice avalanches. Caution is therefore required in the interpretation of the obtained runout zones and other parameters such as velocities or flow depths.

\subsection{Input parameters}

The main input parameters for the calculation of ice avalanches with RAMMS are the following:

Release volume: The three ice volumes described in the section above were considered. The geome- try of the falling ice masses was chosen as realistically as possible. We assumed that the glacier ice will be broken up during the fall and that the density of the ice will decrease from an estimated 850 to $900 \mathrm{~kg} / \mathrm{m}^{3}$ to about 400 to $500 \mathrm{~kg} / \mathrm{m}^{3}$. We increased the initial ice volume by a factor varying between 1.5 for the maximum and 2.0 for the small ice volumes to compensate for the decrease in density which RAMMS does not consider and an uncertainty in regard of the correct mass distribution in the model calculation.

Snow entrainment: The highest uncertainty in the avalanche dynamics calculations is the estimation of the consequences if an ice mass impacts the snowpack. We approached this problem with the RAMMS entrainment module where the parameter $\mathrm{K}$ controls the entrainment rate of snow (Christen et al. 2010). If the snowpack is stable we applied a small entrainment rate $(K=0.2)$ and a small snow depth, which can be entrained. If the snow pack is unstable an ice avalanche will entrain $1.5 \mathrm{~m}$ of snow by frontal plugging and the secondary release of snow avalanches is likely (Tab. 1). Furthermore we varied the sizes of the areas with possible snow entrainment in relation to the snowpack stability (Fig. 4). To describe the snowpack stability and the release probability of snow avalanches we apply the five danger levels of the European Avalanche Danger scale (SLF 2008).

Friction parameters: The frictional parameters $\mu$ and $\xi$ are implemented in RAMMS. The two parameters were calibrated for snow avalanches in relation to the avalanche volume, terrain features, the elevation and the return period (Tab. 1). We calculated ice as well as combined snow-ice avalanches with the same friction values as for snow avalanches. For small ice volumes and a stable snowpack we used the friction value for small vo- 

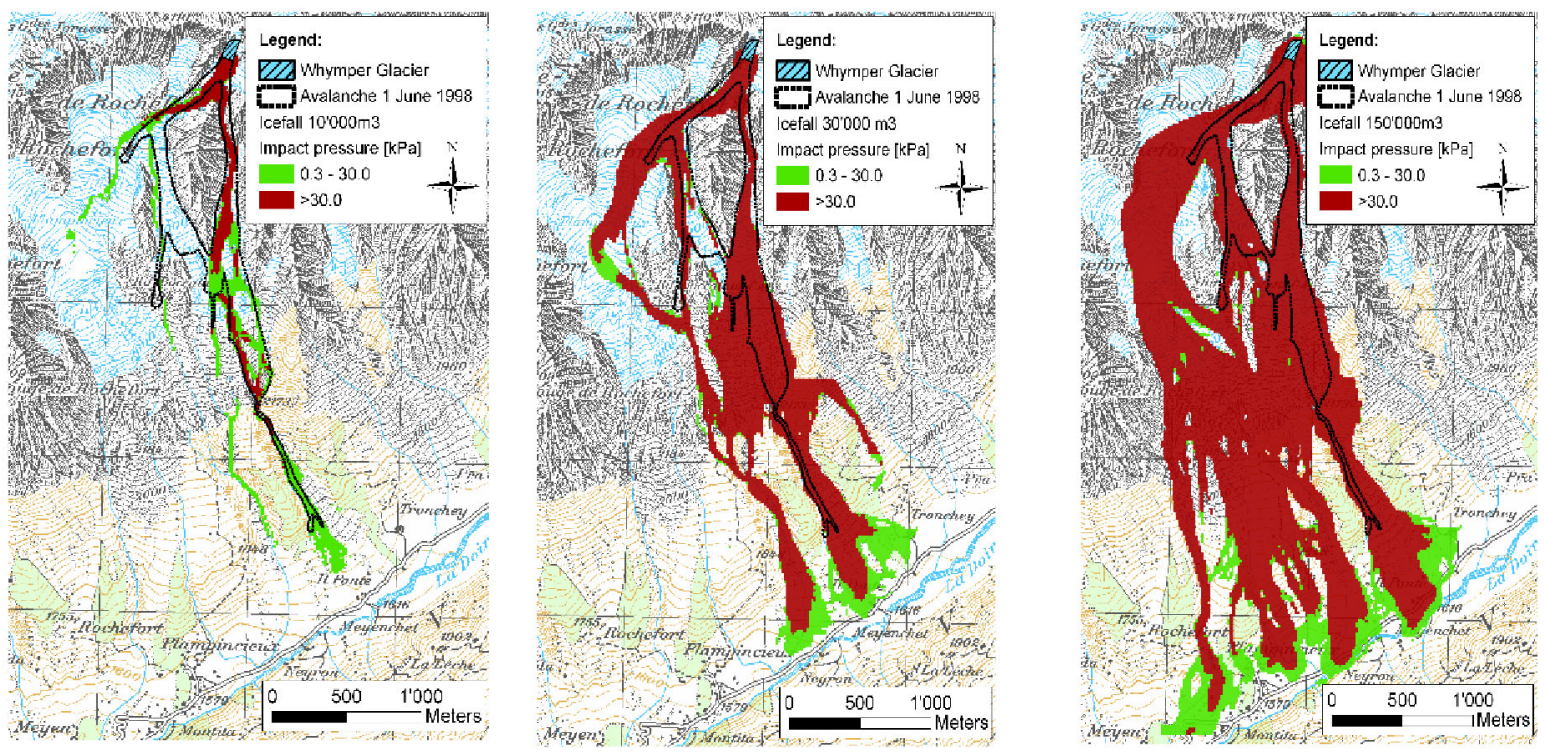

Fig. 5: Results of avalanche dynamics calculations using RAMMS for small, medium and maximum ice volumes (left: icefall $10^{\prime} 000 \mathrm{~m}^{3}$ with danger level "Low"; middle: icefall 30 '000 $\mathrm{m}^{3}$ with danger level "Considerable"; right: icefall 150'000 $\mathrm{m}^{3}$ with danger level "High")

lumes and a 10 year return period. For extreme situations when the ice avalanche releases large snow masses we used the most extreme friction values for large volumes and a 300 year return period.

\subsection{Results}

At first we tested the performance of RAMMS by back-calculation of the June 1998 ice avalanche. The initial release volume was set at $260 ' 000 \mathrm{~m}^{3}$ which is 1.7 higher than the observed ice volume of $1501000 \mathrm{~m}^{3}$. The best fit frictional parameters for the runout were achieved using $\mu=$ 0.35 and $\xi=1350 \mathrm{~m} / \mathrm{s}^{2}$. The RAMMS simulation reproduced the extent along the main avalanche axis relatively well. However the lateral spreading on the Planpincieux glacier and in the lower part of the avalanche path was too big. This could be due to the fact that the Digital Elevation Model of 2005 does not sufficiently represent the topography of 1998 (Fig. 2).

We calculated 14 different scenarios with RAMMS for the hazard assessment (Fig. 5). According to the calculations the danger level "Considerable" is the threshold at which the valley bottom can be endangered by an icefall with a volume of $10^{\prime} 000 \mathrm{~m}^{3}$. The entrainment volumes vary from $10,000 \mathrm{~m}^{3}$ for a stable snowpack (Danger level "Low") to over 900 '000 $\mathrm{m}^{3}$ for an extreme avalanche situation with an unstable snowpack. If an icefall of $30^{\prime} 000 \mathrm{~m}^{3}$ occurs during a time period with a stable snowpack (danger level "Low") the dense part of the avalanche does not reach the valley road, but the air pressure of the powder part cannot be neglected. If the snowpack is only moderately to weakly bonded (danger level "Moderate" / "Considerable") around 250 '000 $\mathrm{m}^{3}$ of snow will be entrained and the avalanche reaches the valley bottom along tracks 1 and 2. Ice avalanches with an initial ice volume of $150,000 \mathrm{~m}^{3}$ always reach the valley bottom independently of the danger level. If the danger level is "High" or "Very High" the village of Planpincieux can be endangered. The hazard area is similar to the extent of extreme snow avalanches. If an icefall occurs during a period with a danger level "High" or "Very High" the consequences are also very serious for small initial ice volumes. The icefall is only the trigger for the snow avalanche and the initial volume is not very relevant because the released snow masses are much larger than the ice masses.

\section{SAFETY CONCEPT}

The safety concept recommends temporary safety measures depending on the local avalanche danger level in combination with the volume of an impending icefall from the Whymper glacier (Tab. 2). The zones which have to be closed for a certain scenario are related to a safety plan (Fig. 6). If for example an icefall with a volume of $20,000 \mathrm{~m}^{3}$ is expected and the local ava- 


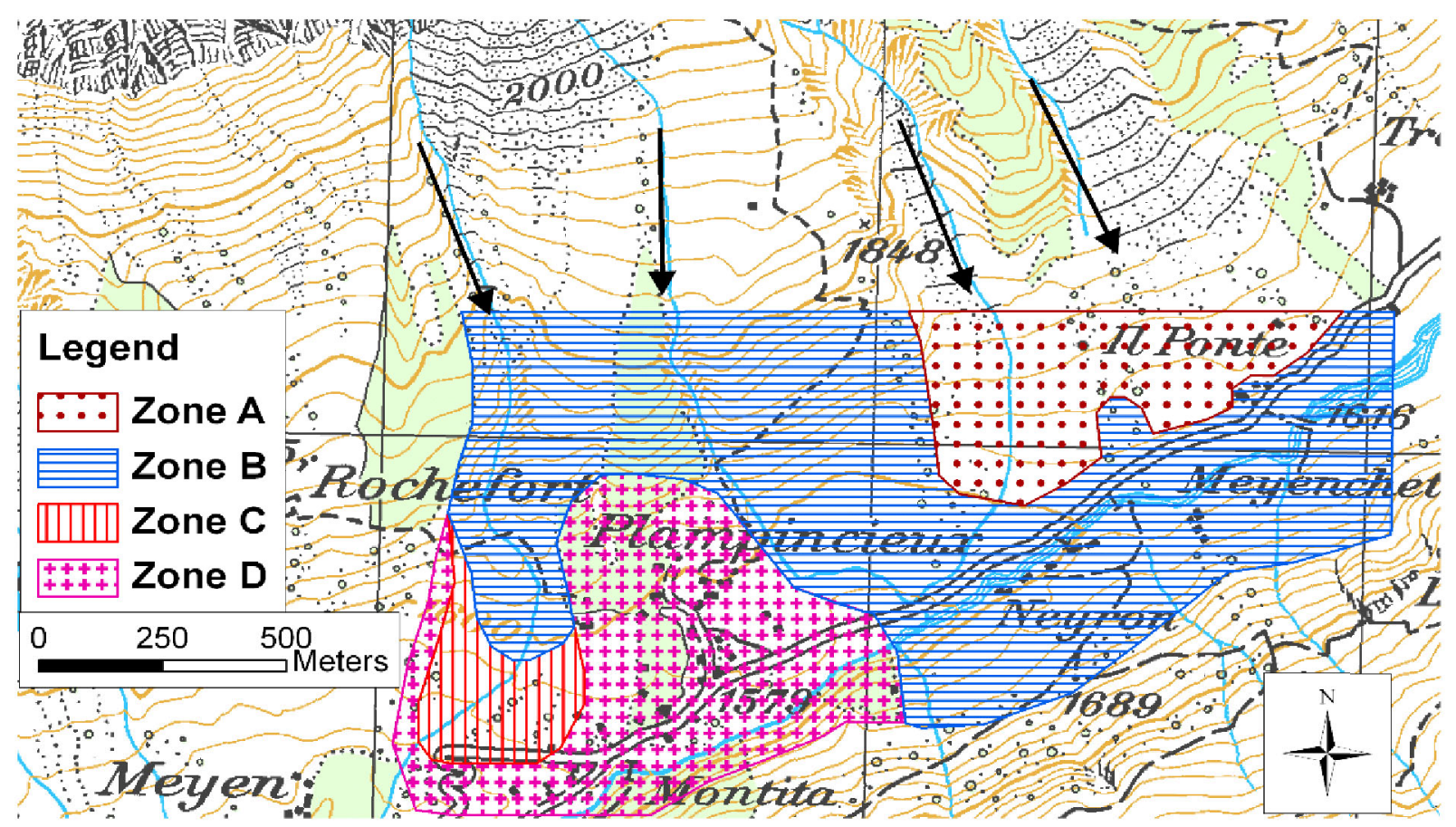

Fig. 6: Safety plan Planpincieux, Val Ferret for ice and snow avalanches from the Whymper glacier. The zones $A, B, C$ and $D$ refer to Tab. 2 and denote the area to be closed in function of the prevailing ice volume and the local avalanche danger level.

lanche danger level in the Val Ferret is "Considerable" we recommend to exclude the zones A and B. Compared to the safety concept established in 1997 we simplified the procedure, included also ice volumes smaller than $10^{\prime} 000 \mathrm{~m}^{3}$ and refined the safety plan. An important input factor is the local avalanche danger level in the Val Ferret. The danger level depends on the snowpack stability, the avalanche triggering probability, the number and extent of dangerous slopes and the potential avalanche volume. An important point is that the impact of an icefall on the snowpack can generate a very large surcharge, which is much higher than the classical additional load (e.g. a group of skiers or an explosion) considered in the definition of European avalanche danger scale (SLF 2008). We recommend therefore to stay a few days longer on the danger level 4 ("High") or 5 ("Very High") than necessary and to evaluate the danger level very carefully if a weak layer is covered by thick snow layers. In the safety concept we have defined three different ice volume categories. The potential volume of an icefall at a specific date has to be assessed with the monitoring system described in the following section.
Tab. 2: Safety concept Planpincieux, Val Ferret for temporary measures during winter. The necessary safety measures are determined in function of the prevailing ice volume which can break loose at the Whymper glacier and the actual avalanche danger level in the Val Ferret.

\begin{tabular}{|c|c|c|c|}
\hline \multirow{2}{*}{$\begin{array}{l}\text { Local } \\
\text { avalanche } \\
\text { danger } \\
\text { level Val } \\
\text { Ferret: }\end{array}$} & \multicolumn{3}{|c|}{ Ice avalanche volume Whymper glacier: } \\
\hline & $<10^{\prime} 000 \mathrm{~m}^{3}$ & $\begin{array}{l}10^{\prime} 000 \mathrm{~m}^{3}- \\
30^{\prime} 000 \mathrm{~m}^{3}\end{array}$ & $\begin{array}{l}30^{\prime} 000 \mathrm{~m}^{3}- \\
150^{\prime} 000 \mathrm{~m}^{3}\end{array}$ \\
\hline 1 Low & $\begin{array}{l}\text { No safety } \\
\text { measures }\end{array}$ & $\begin{array}{l}\text { Exclusion } \\
\text { of zones } A \\
\text { and } B\end{array}$ & $\begin{array}{l}\text { Exclusion of zones } \\
A, B \text { and } C, \text { Curfew } \\
\text { zone D }\end{array}$ \\
\hline $\begin{array}{l}2 \text { Modera- } \\
\text { te }\end{array}$ & $\begin{array}{l}\text { No safety } \\
\text { measures }\end{array}$ & $\begin{array}{l}\text { Exclusion } \\
\text { of zones } A \\
\text { and } B \\
\end{array}$ & $\begin{array}{l}\text { Exclusion of zones } \\
A, B, C \text { and } D\end{array}$ \\
\hline $\begin{array}{l}3 \text { Consid- } \\
\text { erable }\end{array}$ & $\begin{array}{l}\text { Exclusion of } \\
\text { zones A } \\
\text { and evtl. B }\end{array}$ & $\begin{array}{l}\text { Exclusion } \\
\text { of zones } A \\
\text { and } B\end{array}$ & $\begin{array}{l}\text { Exclusion of zones } \\
A, B, C \text { and } D\end{array}$ \\
\hline 4 High & $\begin{array}{l}\text { Exclusion of } \\
\text { zones A, B } \\
\text { and C }\end{array}$ & $\begin{array}{l}\text { Exclusion } \\
\text { of zones A, } \\
\text { B and C, } \\
\text { Curfew } \\
\text { zone D }\end{array}$ & $\begin{array}{l}\text { Exclusion of zones } \\
A, B, C \text { and } D\end{array}$ \\
\hline $\begin{array}{l}5 \text { Very } \\
\text { high }\end{array}$ & $\begin{array}{l}\text { Exclusion of } \\
\text { zones } A, B \text {, } \\
C \text { and } D\end{array}$ & $\begin{array}{l}\text { Exclusion } \\
\text { of zones } A \text {, } \\
B, C, D\end{array}$ & $\begin{array}{l}\text { Exclusion of zones } \\
A, B, C \text { and } D\end{array}$ \\
\hline
\end{tabular}




\section{MONITORING SYSTEM}

In the past the monitoring system of the Whymper glacier consisted of visual observations, aerial photos and topographic measurements. The observations effected in autumn 2008 allowed the opening of a new crevasse to be detected which was the reason behind the investigations presented in this paper. In 2009 a new monitoring system was installed consisting of stakes with prisms on the glacier surface and an automatic total station consisting of a theodolite and a distometer situated in the valley floor (Vagliasindi et al 2010). The monitoring consists of continuous displacement measurements to detect an acceleration of an unstable ice mass. The measurements require good visibility and the placement and durability of the stakes is limited. New technologies were therefore applied and are still being tested to improve the reliability of the monitoring system. Close range photogrammetry techniques were used to quantify the volume of the hanging glacier and the widening of crevasses. A low cost GPS station was installed in order to obtain displacement data in poor weather conditions. In fall 2010 a network with GPS stations will be installed. The analysis of the seismic activity can indicate a potential rupture of a hanging glacier. Combined motion-seismic monitoring systems seem to be a promising way to accurately predict the break-off of a hanging glacier (Faillettaz et al. 2008). Finally a ground based SAR-system (Synthetic Aperture Radar) was tested to infer unstable ice masses and with a GPR (Ground Penetrating Radar) helicopter survey the ice volumes could be determined.

\section{CONCLUSIONS AND OUTLOOK}

The proposed safety concept has been in operation since 2009. During winter 2009/2010 the hanging glacier was moving downwards with a rate of approximately $4 \mathrm{~cm} /$ day and no acceleration was observed. After an intense snow fall period followed by a temperature rise the avalanche danger level was "High" and the valley was closed to the public for one week. At the beginning of April 2010 two small icefalls with an estimated total volume of less than $10,000 \mathrm{~m}^{3}$ occurred. On 10 June 2010 an icefall broke loose from a hanging glacier below the Whymper glacier. The runout was comparable to the icefall of 1 June 1998 but the ice volume may have been much smaller. Another icefall of approximately 5000 to $6000 \mathrm{~m}^{3}$ occurred at the end of July 2010.
The uncertainties in the analysis of snow/ice-avalanche processes are rather high. In particular the interaction of ice avalanches with the snowpack and the assessment of the consequences are still poorly known. Careful monitoring and analysis of future icefalls in winter at the Whymper glacier and other locations will improve the existing knowledge.

The safety concept can only be applied if the volume of an impending icefall is known. Further improvements in the assessment of the avalanche hazard and the evolution of the dynamics of hanging glaciers in a changing climate are necessary.

The application of the avalanche calculation model RAMMS delivered very promising results. However the model is not yet well calibrated for the calculation of ice avalanches. The calibration of RAMMS could be improved with modeling studies based on observed ice avalanches with different volumes and ground roughness.

\section{REFERENCES}

Christen, M., Kowalski, J. and Bartelt, P., 2010. RAMMS: Numerical simulation of dense snow avalanches in three-dimensional terrain, Cold Regions Science and Technology, Volume 63, Issues 1-2, August 2010, Pages 1-14, ISSN 0165-232X, DOI: 10.1016/j.coldregions. 2010.04.005.

Deline, P., 2009. Interactions between rock avalanches and glaciers in the Mont Blanc massif during the late Holocene. Quaternary Science Reviews, 28 (11-12), 1070-1083. DOI: 10.1016/j.quascirev.2008.09.025.

Deline, P., Broccolato, M., Noetzli, J., Ravanel, L. and Tamburini, A., 2010. The December 2008 Crammont rock avalanche, Mont Blanc massif area, Italy. Geophysical Research Abstracts Vol. 12, EGU2010-10388, 2010.

Faillettaz, J., Pralong, A., Funk, M. and Deichmann, N., 2008. Evidence of logperiodic oscillations and increasing icequake activity during the breaking-off of large ice masses. Journal of Glaciology, 57, (187), 725.

Margreth, S., 2009. Hazard from ice avalanches from the Whymper glacier, Gr. Jorasses Val Ferret, Courmayeur, Italy. SLF Expert Report G2009.08, unpublished.

Margreth, S. and Funk, M., 1999. Hazard mapping for ice and combined snow/ice avalanches: two case studies from the Swiss and Italian Alps. Cold Reg. Sci. Technol., 30(1-3), 159173. 
Pralong, A. and Funk, M., 2006. On the instability of avalanching glaciers. J. Glaciol., 52(176), 31-48.

Raymond, M., Wegmann, M. and Funk, M., 2003. Inventar gefährlicher Gletscher in der Schweiz. Eidg. Tech. Hochschule, Zurich. Versuchsanst. Wasserbau, Hydrol. Glaziol. Mitt. 182.

SLF, 2010. RAMMS 1.3.0 (Rapid Mass Movements) - A modeling system for snowavalanches in research and practice. USER MANUAL v1.01. WSL Institute for Snow and Avalanche Research SLF. Davos. 2010. pp. 96.

SLF (Publisher), 2008. Avalanche Bulletins and other products. Interpretation Guide. Edition 2008. WSL Institute for Snow and Avalanche Research SLF. Pp. 40.

SLF, 2005. AVAL-1D Manual. WSL Institute for Snow and Avalanche Research SLF. 2005. Davos. pp. 89 and annexes A-E.

Vagliasindi, M., Funk, M., Faillettaz, J., Dalban, P., Lucianaz, C., Diotri, F., Motta, E. and Margreth, S., 2010. Monitoring of Grandes Jorasses hanging glacier (Aosta Valley, Italy): improving monitoring techniques for glaciers instability. Geophysical Research Abstracts. Vol. 12, EGU2010-9973, 2010. 